\title{
INFLUÊNCIA DO TIPO DE CILINDRO DE TRABALHO NA PRODUTIVIDADE DO NOVO LAMINADOR DE ACABAMENTO DA USIMINAS-CUBATÃO*
}

Marcelo Souza de Oliveira ${ }^{1}$
Camila Ribeiro dos Santos $^{2}$
Leilane Souza de Camargo ${ }^{3}$

\section{Resumo}

Os cilindros de laminação, em conjunto com outras variáveis de processo, exercem influência direta no resultado de qualidade do produto e produtividade da linha de laminação. No caso do Novo Laminador de Acabamento da Usiminas-Cubatão, a especificação original de projeto definiu para utilização, cilindro de trabalho em material aço forjado. No entanto como havia dúvidas sobre a adequação deste material para esta aplicação específica, foi viabilizado teste de cilindro de material ferro fundido. O objetivo deste trabalho é comparar o desempenho entre os dois tipos de cilindros e a influência no resultado de produtividade da linha de laminação do Novo Laminador de Acabamento da Usiminas-Cubatão. Foi considerada a garantia da qualidade do produto final durante os testes feitos com este tipo de material do cilindro.

Palavras-chave: Cilindro; Laminação; Laminador de acabamento.

\section{INFLUENCE OF THE WORK ROLL TYPE IN THE PRODUCTIVITY OF THE NEW HOT SKIN PASS MILL LINE AT USIMINAS-CUBATÃO WORKS}

\section{Abstract}

The rolling mill work rolls, associated with other process variables, have a direct influence over the product quality results and rolling mill line productivity. It was originally specified that the new hot skin pass mill at Usiminas-Cubatão would use forged steel work rolls. However, as there were doubts about the adequacy of this material for this specific application, a test using cast iron work rolls was proposed and carried out. The objective of this paper is to compare and evaluate the performance of both kinds of work mill rolls and their influence over the productivity results of the new hot skin mill line at Usiminas-Cubatão. Quality assurance for the final product was a capital aspect not forgotten during the tests done with these work roll types.

Keywords: Roll; Mill; Hot skin pass.

1 Engenheiro Mecânico, Especialista na Gerência de Suporte Técnico da Laminação a Quente, Usiminas, Membro da ABM, Cubatão SP, Brasil.

2 Engenheira de Materiais, Engenheira de Produção Pleno na Gerência de Suporte Técnico da Laminação a Quente, Usiminas, Membro da ABM, Cubatão SP, Brasil.

3 Engenheira de Produção, Engenheira de Produção na Gerência de Suporte Técnico da Laminação a Quente, Usiminas, Membro da ABM, Cubatão SP, Brasil

\footnotetext{
* Contribuição técnica ao $51^{\circ}$ Seminário de Laminação - Processos e Produtos Laminados e Revestidos, 28 a 31 de outubro de 2014, Foz do Iguaçu, PR, Brasil.
} 


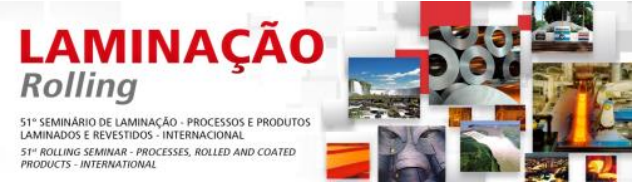

\section{INTRODUÇÃO}

O laminador de acabamento de bobina a quente tem como principal propósito alcançar propriedades mecânicas adequadas e melhorar o aplainamento da tira (bobina) [1].

O Novo Laminador de Acabamento da Usiminas-Cubatão entrou em operação em setembro de 2012, projetado para laminar bobinas oriundas do Laminador de Tiras a Quente 2 da Usiminas-Cubatão, que teve o seu startup em março de 2012. A configuração do Novo Laminador de Acabamento da Usiminas-Cubatão é do tipo $4 \mathrm{Hi}$ ( 2 cilindros de encosto e 2 cilindros de trabalho), Figura 1, com uma cadeira, equipado com HAGC-cylinders, que tem a função de posicionamento de abertura dos cilindros (espessura da tira) e resposta para o controle de alongamento da tira, bending positivo e negativo para o controle de forma e planicidade da tira. $O$ processo de laminação é a seco. As principais características estão apresentadas na Tabela 1 e na Tabela 2, as especificações para o material a ser laminado.

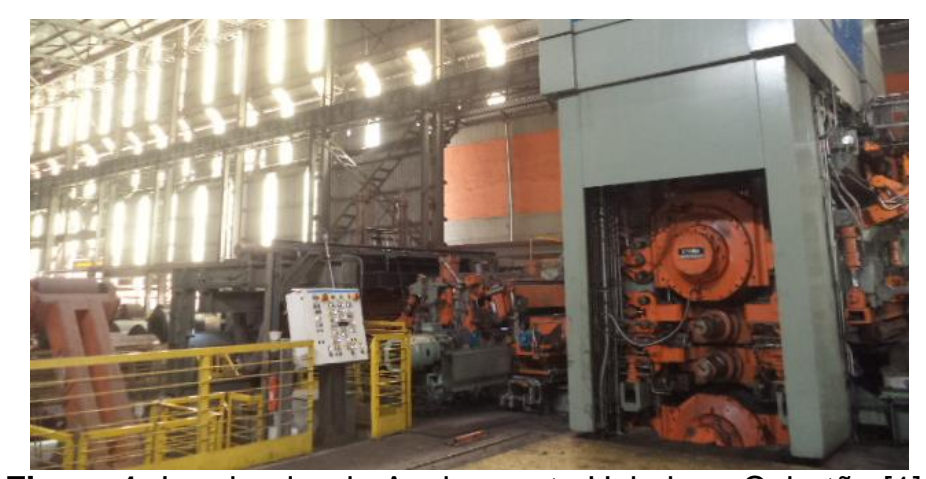

Figura 1: Laminador de Acabamento Usiminas-Cubatão [1].

Tabela 1. Características básicas do Laminador de Acabamento da Usiminas-Cubatão [1].

\begin{tabular}{|l|l|}
\hline \multicolumn{1}{|c|}{ Característica } & \multicolumn{1}{|c|}{ Valor } \\
\hline Máximo alongamento & $3 \%$ \\
\hline Potência Nominal Total $(\mathrm{kW})$ & 2300 \\
\hline Torque Nominal Motor $\left(\mathrm{kN}^{\star} \mathrm{m}\right)$ & 29,3 \\
\hline Velocidade Base Motor $(\mathrm{rpm})$ & 750 \\
\hline Velocidade Máxima Motor (rpm) & 1500 \\
\hline Máxima velocidade para diâmetro mínimo do cilindro de trabalho $(\mathrm{mpm})$ & 554 \\
\hline Máxima velocidade para diâmetro máximo do cilindro de trabalho $(\mathrm{mpm})$ & 624 \\
\hline
\end{tabular}

Tabela 2. Especificações para o material a ser laminado [1].

\begin{tabular}{|l|l|}
\hline \multicolumn{1}{|c|}{ Especificação } & \multicolumn{1}{c|}{ Valor } \\
\hline Espessura de material & 1,2 a $6,5 \mathrm{~mm}{ }^{*}$ \\
\hline Largura & 700 a $2050 \mathrm{~mm}$ \\
\hline Peso máximo da bobina & 35 ton \\
\hline Máxima temperatura da bobina (entrada) & $40^{\circ} \mathrm{C}$ \\
\hline Peso específico da bobina (PIW) & máximo $24,0 \mathrm{~kg} / \mathrm{mm}$ \\
\hline Grau do aço & Alta, média e baixa resistência \\
\hline Limite de escoamento máximo & $700 \mathrm{MPa}$ \\
\hline
\end{tabular}

A Tabela 3 apresenta a especificação geral dos cilindros de laminação do Laminador de Acabamento. 


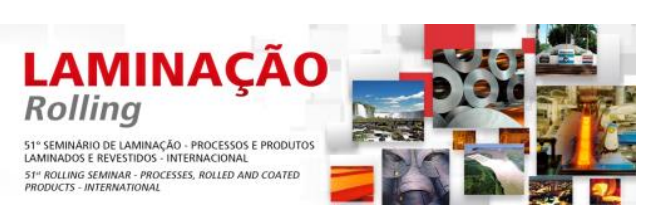

Para as características do Laminador de Acabamento da Usiminas-Cubatão, do material a ser processado e dos cilindros de laminação especificados, a produtividade com relação à tonelagem de troca de cilindros, teve como principais parâmetros definidos em projeto:

- Cilindro de Trabalho: Campanha de laminação de 600 t e 0,6mm de redução no diâmetro.

- Cilindro de Encosto: Campanha de laminação de 20000 t e 2,0mm de redução no diâmetro.

Tabela 3. Especificação dos cilindros do Laminador de Acabamento

\begin{tabular}{|l|c|c|c|c|c|c|c|}
\hline \multicolumn{1}{|c|}{ Item } & Material & $\begin{array}{c}\varnothing \\
\text { máximo }\end{array}$ & $\begin{array}{c}\varnothing \\
\text { mínimo }\end{array}$ & $\begin{array}{c}\text { Comprimento } \\
\text { total da mesa }\end{array}$ & $\begin{array}{c}\text { Comprimento } \\
\text { total }\end{array}$ & Dureza & Peso \\
\hline $\begin{array}{l}\text { Cilindro de } \\
\text { Trabalho }\end{array}$ & $\begin{array}{c}\text { Aço } \\
\text { forjado }\end{array}$ & $450 \mathrm{~mm}$ & $400 \mathrm{~mm}$ & $2280 \mathrm{~mm}$ & $4722 \mathrm{~mm}$ & $\begin{array}{c}95 / 98 \\
\text { HFRSc }\end{array}$ & $3,8 \mathrm{t}$ \\
\hline $\begin{array}{l}\text { Cilindro de } \\
\text { Encosto }\end{array}$ & $\begin{array}{c}\text { Aço } \\
\text { forjado }\end{array}$ & $\begin{array}{c}1190 \\
\mathrm{~mm}\end{array}$ & $\begin{array}{c}1050 \\
\mathrm{~mm}\end{array}$ & $2280 \mathrm{~mm}$ & $4874 \mathrm{~mm}$ & $\begin{array}{c}60 / 65 \\
\text { HSc }\end{array}$ & $25,5 \mathrm{t}$ \\
\hline
\end{tabular}

A produção anual do escopo de projeto é de 800.000 t e eficiência de $80 \%$. Com estes dados e a tonelagem de campanha do cilindro de trabalho em 600 t, teremos:

-Produção mensal $=67.000 \mathrm{t}$

-Produção diária $=2393 \mathrm{t}$

-Quantidade de trocas de cilindros de trabalho por dia $=(2393 / 600)=4$ trocas $/$ dia .

O quadro apresentado de 4 trocas/dia de cilindros de trabalho, correspondendo a 8 usinagens por dia, fez surgir a necessidade de se procurar alternativas de melhorar esta produtividade, visto que não teríamos tempo de máquina (retífica de cilindros) suficiente para atender esta demanda e a do Laminador de Tiras a Quente 2 da Usiminas-Cubatão.

Aumentar a produtividade do Laminador de Acabamento, diminuindo a quantidade de trocas de cilindros de trabalho, ou seja, aumentando a tonelagem (quantidade de bobinas) por campanha, pode ser alcançado por ações no processo, no planejamento da sequência de laminação ou da substituição do tipo de material do cilindro de trabalho por um de maior resistência ao desgaste. A opção foi a de testar outro material de cilindro.

Um fator importante com o teste de outro material de cilindro é a analise da influência na qualidade e o item escolhido foi o "Retrabalho", ou seja, é uma relaminação para corrigir problema de aplainamento de material que já havia sido processado. Os problemas de aplainamento são:

- Ondulado Total (OT)

- Ondulado Intermediário (OI)

- Ondulado Lateral (OL)

- Ondulado Central (OC)

$\mathrm{O}$ ondulado tem como origem a diferença no perfil de entrada do material e o de saída, assim, todas as porções ao longo da largura não terão o mesmo comprimento final; algumas partes do produto ficam tracionadas e outras comprimidas. Se estas tensões longitudinais introduzidas forem suficientemente grandes, haverá por deformação elástica ou plástica, uma flambagem localizada com a formação de ondulados [2]. * Contribuição técnica ao $51^{\circ}$ Seminário de Laminação - Processos e Produtos Laminados e
Revestidos, 28 a 31 de outubro de 2014, Foz do Iguaçu, PR, Brasil. 


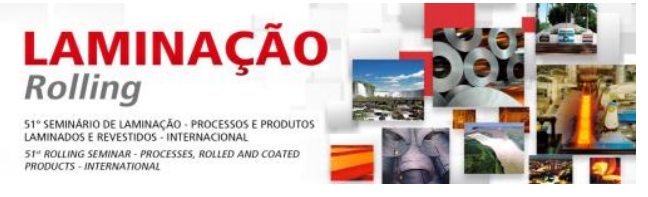

\section{MATERIAL E MÉTODOS}

O teste com outro material de cilindro não se apresentou como uma solução simples, devido ao dimensional do cilindro de trabalho de diâmetro pequeno ser um componente de dificuldade no processo de fabricação de cilindros fundidos centrifugados. Essas dificuldades são [3]:

-Garantir a formação do tubo de metal líquido por meio de força centrífuga até a solidificação do metal. Diâmetro baixo do cilindro necessita de altas rotações na centrífuga para garantir a força.

- Garantir a união da interface com o núcleo para que tenha propriedades suficientes para suportar os esforços de laminação.

-Para materiais mais ligados como Alto Cromo ou Aço Rápido, haveria pouco material de núcleo para garantir a perfeita interface que evitaria a contaminação do material da casca no núcleo, o que fragiliza o cilindro.

Colocamos para teste, 2 pares de cilindros de material Ferro Fundido Microligado, com processo de fabricação centrifugado.

A dureza fornecida foi na faixa de 78 a 82 Shore $C$.

A dureza dos cilindros de aço forjado, conforme projeto, foram fornecidos na faixa de 90 a 92 Shore C.

As características técnicas, composição química (Tabela 4) e propriedades (Tabela 5), por tipo de material do cilindro, nos mostra que os materiais apresentam valores bem distintos. Uma consideração a ser feita é a de que o cilindro de ferro fundido apresenta limite de resistência mecânica menor, o que levaria à necessidade de maiores dimensões para suportar as tensões internas geradas em um mesmo trabalho, porém, no laminador de acabamento, as tensões internas no cilindro são praticamente desprezíveis em relação à carga.

Uma propriedade relevante que não está presente na tabela 5 , seria a tenacidade à fratura, que mede o comportamento do material em resistir esforços mecânicos em presença de uma trinca existente. Comparativamente, um ferro fundido possui também menor tenacidade à fratura em relação a um aço forjado, mas a velocidade de propagação de uma trinca num aço forjado é superior ao ferro fundido por não possuir qualquer tipo de bloqueio microestrutural [3].

Tabela 4. Composição Química para cilindro de Aço Forjado(AFJ) e Ferro Fundido(FoFo) [3].

\begin{tabular}{|c|c|c|c|c|c|c|c|c|c|}
\hline \multicolumn{10}{|c|}{ Composição Química (média) } \\
\hline Liga & $\mathrm{C}$ & $\mathrm{Si}$ & $\mathrm{Mn}$ & $\mathrm{Ni}$ & $\mathrm{Cr}$ & $\mathrm{Mo}$ & $\mathrm{V}$ & $\mathrm{W}$ & $\mathrm{Nb}+\mathrm{Ti}$ \\
\hline AFJ & 0,83 & 0,44 & 0,45 & - & 3,00 & 0,34 & 0,09 & - & - \\
\hline FoFo & 3,30 & 0,90 & 0,87 & 4,50 & 1,80 & 0,47 & 1,50 & 1,50 & 3,00 \\
\hline
\end{tabular}

Tabela 5. Propriedades dos cilindros de Aço Forjado(AFJ) e Ferro Fundido(FoFo) [3].

\begin{tabular}{|c|c|c|c|c|c|c|c|c|}
\hline Material & $\begin{array}{c}\text { Módulo } \\
\text { de } \\
\text { Young } \\
\mathrm{GPa}\end{array}$ & $\begin{array}{c}\text { Coef. } \\
\text { de } \\
\text { Dilatação } \\
10^{-6} / \mathrm{K}\end{array}$ & $\begin{array}{c}\text { Condutividade } \\
\text { Térmica } \\
(\mathrm{W} / \mathrm{mK})\end{array}$ & $\begin{array}{c}\text { Limite de } \\
\text { Resistência } \\
(\mathrm{MPa})\end{array}$ & $\begin{array}{c}\text { Limite de } \\
\text { Escoamento } \\
(\mathrm{MPa})\end{array}$ & $\begin{array}{c}\text { Densidade } \\
\mathrm{kg} / \mathrm{m}^{3}\end{array}$ & $\begin{array}{c}\text { Calor } \\
\text { Específico } \\
\mathrm{J} / \mathrm{kg} . \mathrm{K}\end{array}$ & $\begin{array}{c}\text { Coeficiente } \\
\text { de Poison }\end{array}$ \\
\hline AFJ & 210 & 12 & 45 & 1200 & 1000 & 7800 & 480 & 0,29 \\
\hline FoFo & 180 & 14,5 & 25 & 465 & & 7450 & 470 & 0,3 \\
\hline
\end{tabular}

A utilização do cilindro de Ferro Fundido seguiu os mesmos parâmetros, coroa e rugosidade do cilindro de Aço Forjado.

Os dados para a análise do resultado de desempenho do cilindro de ferro fundido e do aço forjado foram:

\footnotetext{
* Contribuição técnica ao $51^{\circ}$ Seminário de Laminação - Processos e Produtos Laminados e Revestidos, 28 a 31 de outubro de 2014, Foz do Iguaçu, PR, Brasil.
} 


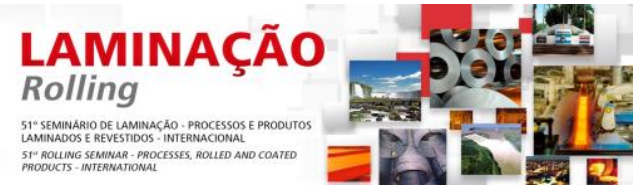

- Diâmetro; (medição automática na retífica)

- Perfil de desgaste; (medição automática na retífica)

- Tonelagem de campanha;

- Rendimento de cilindro (t/mm);

- Tonelagem e quantidade de material (bobina) retrabalhado no laminador.

Os registros dos dados foram feitos em sistema de controle, correlacionando com as campanhas feitas no laminador.

O Perfil de desgaste é medido na retífica após a campanha de laminação em um comprimento de mesa de $2075 \mathrm{~mm}$ (Comprimento total da mesa $2280 \mathrm{~mm}$ ), portanto, aproximadamente $100 \mathrm{~mm}$ de cada borda, não é feita a medição:

\section{RESULTADOS}

\subsection{Participação na Tonelagem Laminada (Figura 2) e Rendimento por Tipo de Material do Cilindro (Figura 3)}

No período de janeiro de 2014 a junho de 2014, o cilindro de Ferro Fundido (FoFo) teve uma participação no acumulado de $31 \%$, ou seja, percentual laminado pelos cilindros de Ferro Fundido em relação a produção do período e o Aço Forjado (AFJ), com participação de 69\%, conforme mostra a Figura 2.

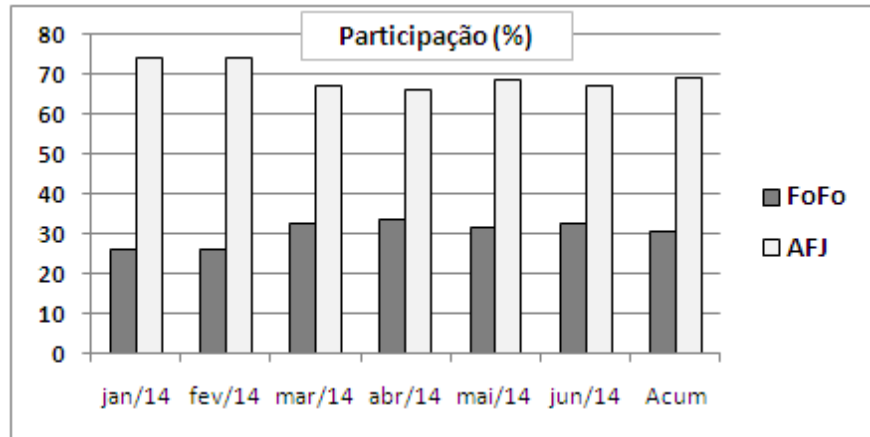

Figura 2. Participação percentual em relação a tonelagem laminada

O Rendimento, tonelagem laminada dividido pelos milímetros consumidos, apurado neste mesmo período, é mostrado na Figura 3.

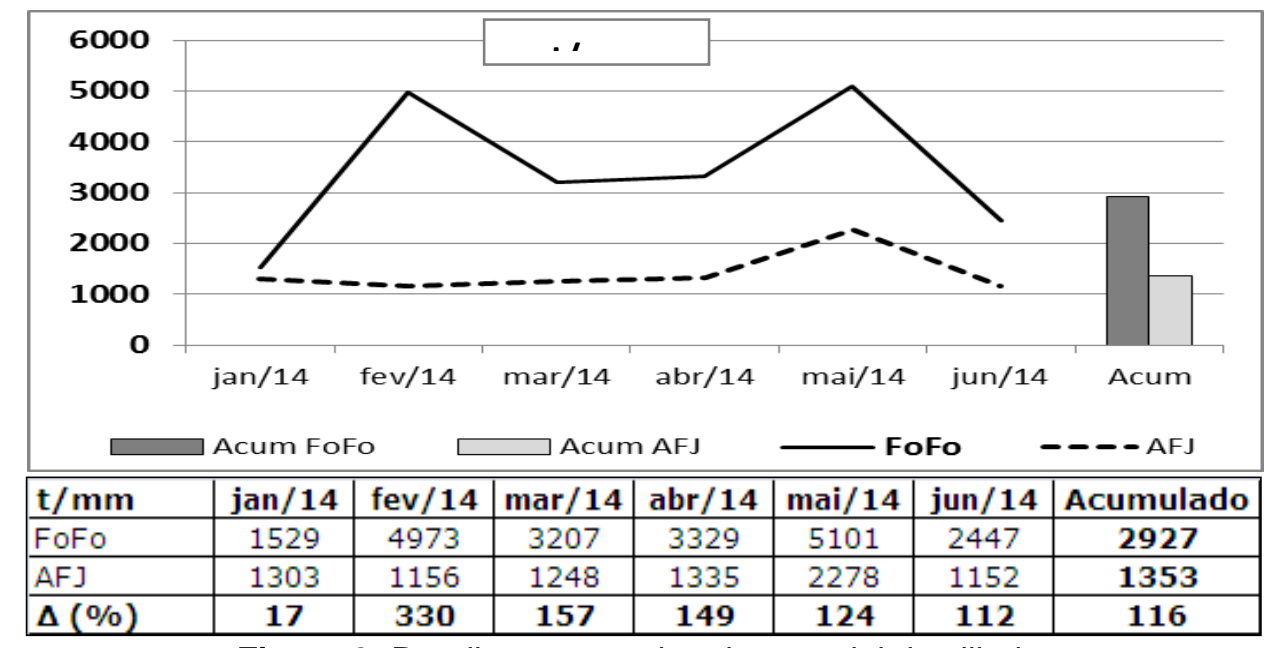

Figura 3. Rendimento por tipo de material do cilindro

* Contribuição técnica ao $51^{\circ}$ Seminário de Laminação - Processos e Produtos Laminados e Revestidos, 28 a 31 de outubro de 2014, Foz do Iguaçu, PR, Brasil. 


\subsection{Tonelagem Média por Campanha (Figura 4)}

Consiste no resultado da divisão da tonelagem laminada por tipo de cilindro pela respectiva quantidade de campanhas. A tonelagem média por campanha do cilindro de Ferro Fundido foi maior 154\% em relação ao de Aço Forjado.

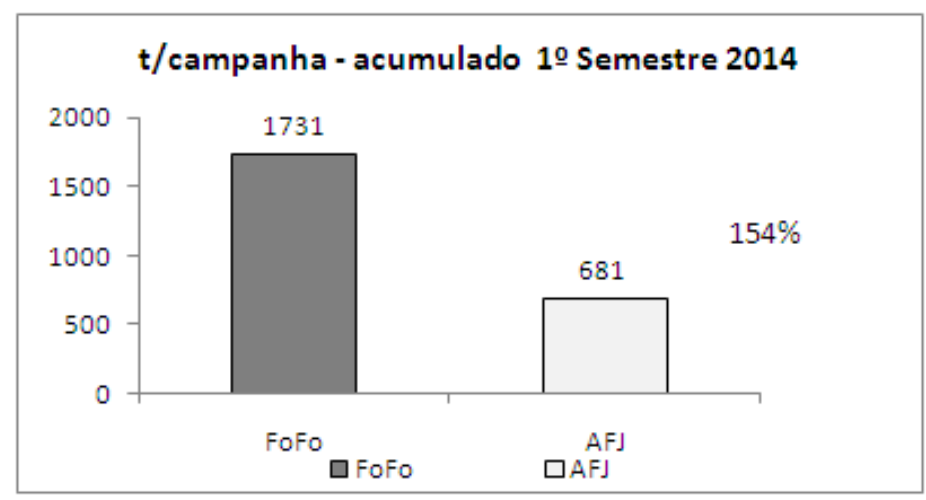

Figura 4. Tonelagem por Campanha

\subsection{Desgaste de Laminação}

É a diferença entre o diâmetro que o cilindro laminou na campanha e o diâmetro inicial medido na retífica exatamente após a campanha, ou seja, é o desgaste ocorrido durante a campanha, como mostrado na Figura 5, por tipo de material do cilindro. O valor dos diâmetros é medido no centro do cilindro.

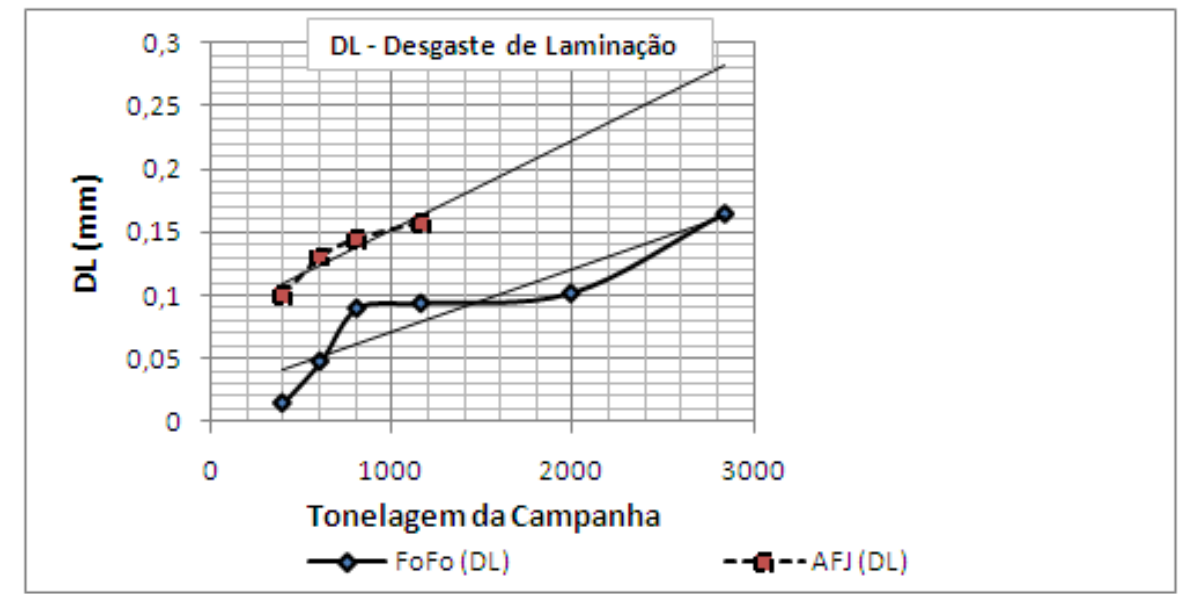

Figura 5. Desgaste de Laminação por tipo de material do cilindro

\subsection{Perfil de Desgaste dos Cilindros (Figura 6 e 7)}

Nas Figuras, é mostrada a curva de perfil médio de desgaste para campanhas médias de 500 toneladas (Figura 6) e para 1000 toneladas de campanha média (Figura 7).

\footnotetext{
* Contribuição técnica ao $51^{\circ}$ Seminário de Laminação - Processos e Produtos Laminados e Revestidos, 28 a 31 de outubro de 2014, Foz do Iguaçu, PR, Brasil.
} 


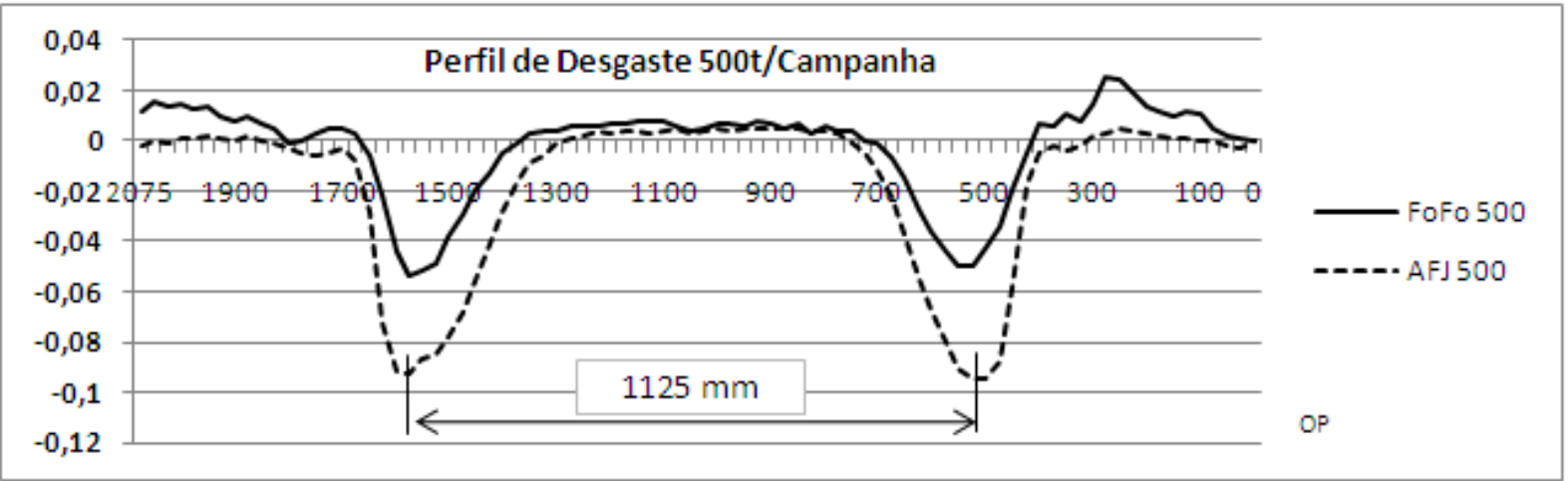

Figura 6. Perfil médio de desgaste para 500 toneladas de Campanha

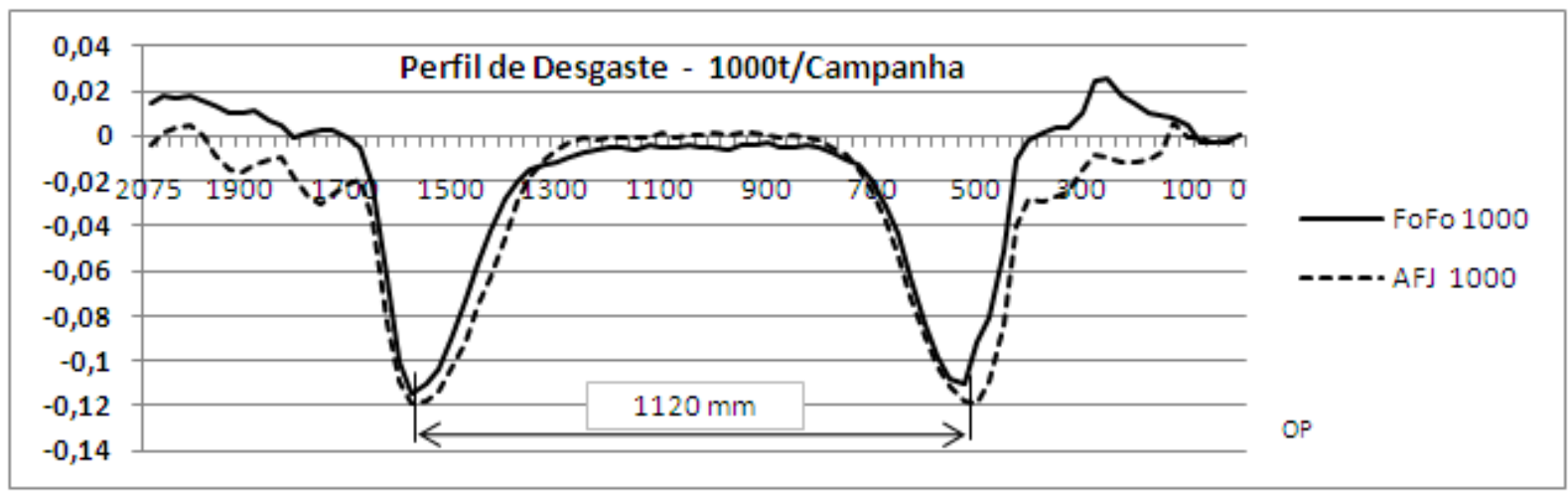

Figura 7. Perfil médio de desgaste para 1000 toneladas de Campanha

\subsection{Influência do Tipo de Material do Cilindro no Índice de Retrabalho}

O Período analisado para correlacionar a quantidade e tonelagem de bobinas que sofreram retrabalho no laminador de acabamento por tipo de material de cilindro que respectivamente processou o produto, foi de janeiro de 2014 a abril de 2014.

A nomenclatura OI refere-se a ondulado intermediário, OL a ondulado lateral, OT a ondulado total e OC a ondulado central.

A Figura 8 relaciona o percentual da tonelagem de produto retrabalhado pela tonelagem laminada por tipo de material do cilindro; já a Figura 9 é o percentual da quantidade de bobinas retrabalhadas pela quantidade de bobinas processadas por tipo de material do cilindro.

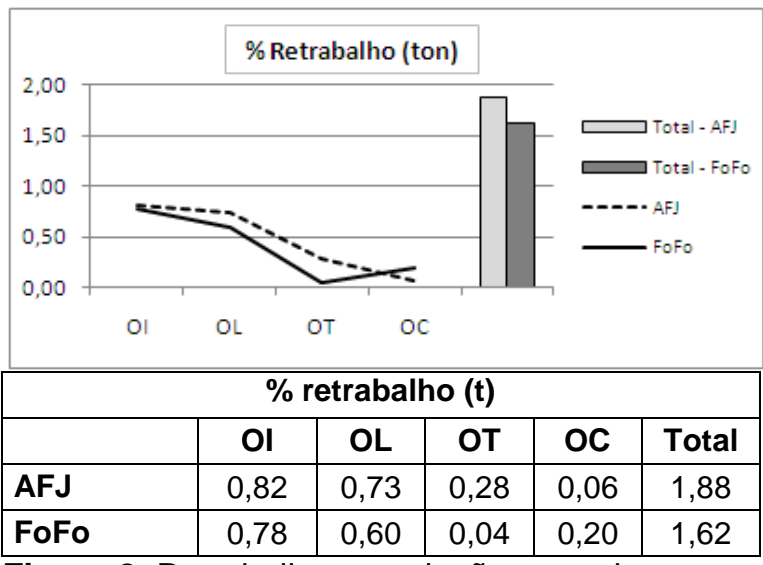

Figura 8: Retrabalho em relação a tonelagem

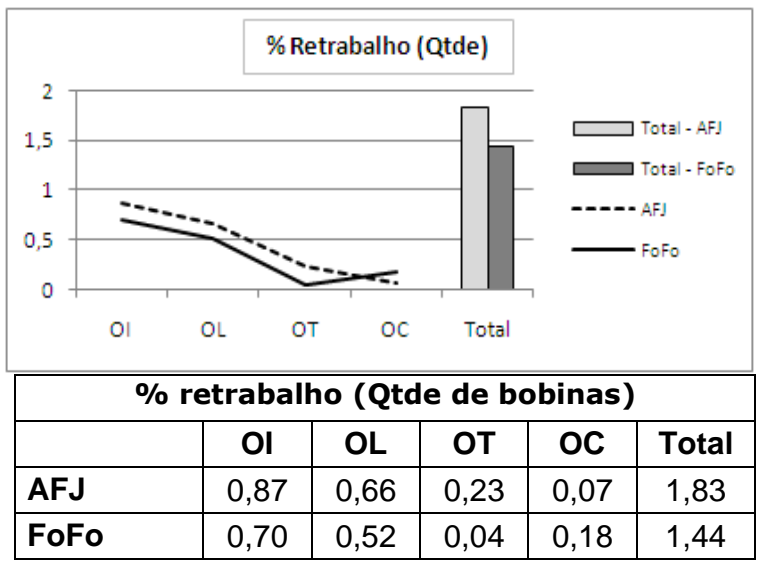

Figura 9: Retrabalho em relação a quantidade * Contribuição técnica ao $51^{\circ}$ Seminário de Laminação - Processos e Produtos Laminados e
Revestidos, 28 a 31 de outubro de 2014, Foz do Iguaçu, PR, Brasil. 


\section{LAMINAÇÃO

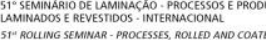

\section{DISCUSSÃO}

Com uma participação significativa de $31 \%$ do cilindro de Ferro Fundido no $1^{\circ}$ semestre de 2014, evidenciou-se através dos resultados, que a performance do cilindro de Ferro Fundido foi superior ao do Aço Forjado em 116\%, com rendimento médio acumulado de 2927t/mm, comparado a $1353 \mathrm{t} / \mathrm{mm}$ do Aço Forjado.

Esta performance relacionada a um menor desgaste do cilindro de Ferro Fundido, possibilitou a operação do laminador de acabamento aumentar para este tipo de material de cilindro a tonelagem da campanha, ficando o resultado do cilindro de Ferro Fundido com tonelagem média por campanha de 1731t, superior em 154\% comparado ao de Aço Forjado, 681t/campanha.

O menor desgaste pode ser também comprovado na Figura 5, do Desgaste de Laminação, onde o patamar para o Aço Forjado encontra-se $60 \%$ maior que o do Ferro Fundido.

Com o objetivo de compreender melhor o desgaste diferenciado dos tipos de materiais dos cilindros, foi elaborada uma análise para caracterização do mecanismo de desgaste.

A caracterização foi feita em um cilindro de Aço Forjado e um de Ferro Fundido, após utilização no laminador de acabamento e antes do processo de retificação.

Utilizado microscópio óptico portátil na região central da mesa dos cilindros, conforme mostra a Figuras 10 [3].

A Tabela 6 apresenta os dados da tonelagem da campanha, rugosidades e dureza macroscópica.

Tabela 6. Dados dos cilindros de Aço Forjado e Ferro Fundido [3].

\begin{tabular}{|l|c|c|c|c|c|}
\hline $\begin{array}{c}\text { Tipo } \\
\text { do } \\
\text { Cilindro }\end{array}$ & $\begin{array}{c}\text { Campanha } \\
(\mathrm{t})\end{array}$ & $\begin{array}{c}\mathrm{DL} \\
(\mathrm{mm})\end{array}$ & $\begin{array}{c}\text { Rugosidade } \\
(\mu \mathrm{m} \mathrm{Ra}) \\
\text { retificado }\end{array}$ & $\begin{array}{c}\text { Rugosidade } \\
(\mu \mathrm{m} \mathrm{Ra}) \\
\text { após campanha }\end{array}$ & $\begin{array}{c}\text { Dureza } \\
(\mathrm{LD})\end{array}$ \\
\hline Aço Forjado & 301 & 0,09 & 0,9 & 0,9 & 840 \\
\hline Ferro Fundido & 2877 & 0,18 & 0,7 & 1,7 & 790 \\
\hline
\end{tabular}

Observa-se na figura 10, abaixo, os sulcos da retificação apenas no cilindro de Aço Forjado, enquanto que no cilindro de Ferro Fundido, são observados apenas os carbonetos, que por sua maior dureza, permaneceram em alto relevo.

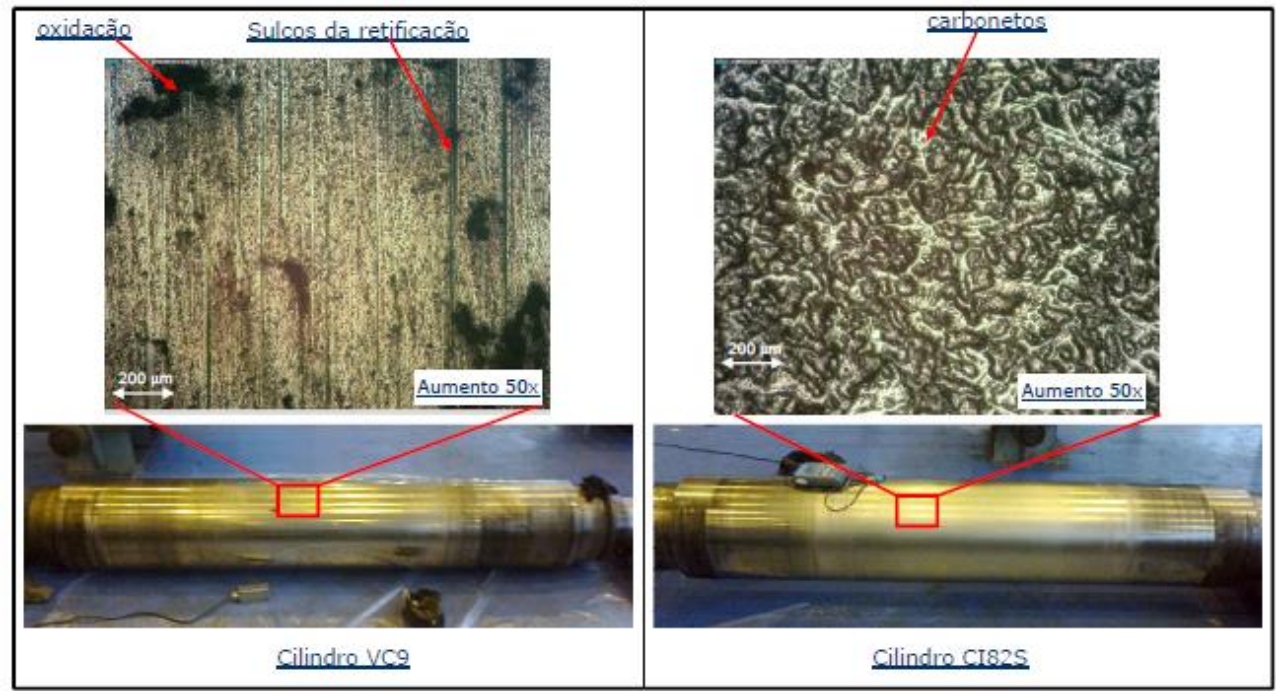

Figura 10: Microestrutura das superfícies de desgaste (50x)

* Contribuição técnica ao $51^{\circ}$ Seminário de Laminação - Processos e Produtos Laminados e Revestidos, 28 a 31 de outubro de 2014, Foz do Iguaçu, PR, Brasil. 
